University of Wollongong

Research Online

Australian Institute for Innovative Materials -

Papers

Australian Institute for Innovative Materials

$1-1-2015$

Electrical stimulation using conductive polymer polypyrrole promotes differentiation of human neural stem cells: a biocompatible platform for translational neural tissue engineering

\author{
Elise Stewart \\ University of Wollongong, elises@uow.edu.au \\ Nao R. Kobayashi \\ University of Wollongong, nao@uow.edu.au \\ Michael J. Higgins \\ University of Wollongong, mhiggins@uow.edu.au \\ Anita Quigley \\ University of Wollongong, anitaq@uow.edu.au \\ Sina S. Jamali \\ University of Wollongong, ssj198@uowmail.edu.au
}

See next page for additional authors

Follow this and additional works at: https://ro.uow.edu.au/aiimpapers

Part of the Engineering Commons, and the Physical Sciences and Mathematics Commons

Research Online is the open access institutional repository for the University of Wollongong. For further information contact the UOW Library: research-pubs@uow.edu.au 


\title{
Electrical stimulation using conductive polymer polypyrrole promotes differentiation of human neural stem cells: a biocompatible platform for translational neural tissue engineering
}

\begin{abstract}
Conductive polymers (CPs) are organic materials that hold great promise for biomedicine. Potential applications include in vitro or implantable electrodes for excitable cell recording and stimulation, and conductive scaffolds for cell support and tissue engineering. Here we demonstrate the utility of electroactive CP Polypyrrole (PPy) containing the anionic dopant dodecylbenzenesulfonate (DBS) to differentiate novel clinically relevant human neural stem cells (hNSCs). Electrical stimulation of PPy(DBS) induced hNSCs to predominantly $\beta$-III Tubulin (Tuj1) expressing neurons, with lower induction of glial fibrillary acidic protein (GFAP) expressing glial cells. In addition, stimulated cultures comprised nodes or clusters of neurons with longer neurites and greater branching than unstimulated cultures. Cell clusters showed a similar spatial distribution to regions of higher conductivity on the film surface. Our findings support the use of electrical stimulation to promote neuronal induction and the biocompatibility of PPy(DBS) with hNSCs, and opens up the possibility of identifying novel mechanisms of fate determination of differentiating human stem cells for advanced in vitro modelling, translational drug discovery and regenerative medicine.
\end{abstract}

\section{Keywords}

translational, polypyrrole, biocompatible, platform, electrical, stimulation, conductive, tissue, polymer, engineering, promotes, differentiation, human, neural, stem, cells

Disciplines

Engineering | Physical Sciences and Mathematics

\section{Publication Details}

Stewart, E., Kobayashi, N. R., Higgins, M. J., Quigley, A. F., Jamali , S., Moulton, S. E., Kapsa, R. M. I., Wallace, G. G. \& Crook, J. M. (2015). Electrical stimulation using conductive polymer polypyrrole promotes differentiation of human neural stem cells: a biocompatible platform for translational neural tissue engineering. Tissue Engineering Part C: Methods, 21 (4), 385-393.

\section{Authors}

Elise Stewart, Nao R. Kobayashi, Michael J. Higgins, Anita Quigley, Sina S. Jamali, Simon Moulton, Robert M. I Kapsa, Gordon G. Wallace, and Jeremy M. Crook 
Electrical Stimulation Using Conductive Polymer Polypyrrole Promotes Differentiation of Human Neural Stem Cells: A Biocompatible Platform for Translational Neural Tissue Engineering

Elise Stewart, BSc (Hons), PhD, ${ }^{1}$ Nao R. Kobayashi, BSc (Hons), $\mathrm{PhD},{ }^{1}$ Michael J. Higgins, BSc (Hons), PhD, ${ }^{1}$ Anita F. Quigley, BSc (Hons), PhD, DipFM, ${ }^{1}$ Sina Jamali, BSc, MSc, MPhil, ${ }^{1}$ Simon E. Moulton, BTech, BSc (Hons), PhD, ${ }^{1}$ Robert M.I. Kapsa, BSc (Hons), PhD, DipFM, ${ }^{1,2}$ Gordon G. Wallace, BSc (Hons), PhD, ${ }^{1}$ Jeremy M. Crook, BSc (Hons), $\mathrm{PhD}^{1,3,4}$,

${ }^{1}$ ARC Centre of Excellence for Electromaterials Science, Intelligent Polymer Research Institute, AIIM Facility, Innovation Campus, University of Wollongong, Squires Way, Fairy Meadow, New South Wales 2519, Australia

${ }^{2}$ Department of Medicine, St Vincent's Hospital, The University of Melbourne, Fitzroy, Victoria 3065, Australia

${ }^{3}$ Department of Surgery, St Vincent's Hospital, The University of Melbourne, Fitzroy, Victoria 3065, Australia

${ }^{4}$ Illawarra Health and Medical Research Institute, University of Wollongong, Wollongong, New South Wales 2522, Australia

Address correspondence to:

Jeremy M. Crook, BSc (Hons), PhD 


\author{
ARC Centre of Excellence for Electromaterials Science, Intelligent Polymer Research \\ Institute, AIIM Facility, Innovation Campus, University of Wollongong, Squires Way, Fairy \\ Meadow, New South Wales 2519, Australia \\ E.mail: jcrook@uow.edu.au \\ jcrook@unimelb.edu.au
}

\begin{abstract}
Keywords
Electrical stimulation; Conductive polymers; Polypyrrole; Human neural stem cells; Differentiation; Modelling; Human neural tissue engineering; Regenerative medicine
\end{abstract}

\begin{abstract}
Conductive polymers (CPs) are organic materials that hold great promise for biomedicine. Potential applications include in vitro or implantable electrodes for excitable cell recording and stimulation, and conductive scaffolds for cell support and tissue engineering. Here we demonstrate the utility of electroactive CP Polypyrrole (PPy) containing the anionic dopant dodecylbenzenesulfonate (DBS) to differentiate novel clinically relevant human neural stem cells (hNSCs). Electrical stimulation of PPy(DBS) induced hNSCs to predominantly $\beta$-III Tubulin (Tuj1) expressing neurons, with lower induction of glial fibrillary acidic protein (GFAP) expressing glial cells. In addition, stimulated cultures comprised nodes or clusters of neurons with longer neurites and greater branching than unstimulated cultures. Cell clusters showed a similar spatial distribution to regions of higher conductivity on the film surface. Our findings support the use of electrical stimulation to promote neuronal induction and the biocompatibility of PPy(DBS) with hNSCs, and opens up the possibility of identifying novel
\end{abstract}


mechanisms of fate determination of differentiating human stem cells for advanced in vitro modelling, translational drug discovery and regenerative medicine.

\section{Introduction}

The advent of stem cell medicine has bolstered interest in the development of cytocompatible CP-based devices for in vitro and in vivo cell-support. Their potential to be used as growth substrates for delivering chemical and non-chemical cues that direct human stem and progenitor cell fate will be especially important. For example, electrostimulation via CPs may be useful to facilitate differentiation of human stem cells to neuronal lineage, with $\mathrm{CP}$ substrates able to support neuronal differentiation of murine embryonic stem cells, and electrical stimulation predisposes cells arising from murine embryoid bodies (EBs) to assume a neuronal fate in vitro, with no GFAP-immunoreactive cells. ${ }^{1-2}$ Not surprisingly, endogenous electric fields occur in vivo in the form of transepithelial cellular potentials or neuronal field potentials, and are important during embryonic and fetal development, as well as wound healing and tissue regeneration. ${ }^{3,5}$ Disturbances to environmental electric fields cause aberrant development. ${ }^{4,6}$ Accordingly, electrical stimulation is increasingly being used as a tool to control stem cell behaviour and function for basic research and future translational application.

PPy is a CP that is easily synthesised and able to incorporate anionic biomolecules (dopants) to enhance biocompatibility and target cellular function. In addition, PPy allows spatiotemporal control of electrical stimulation and generates minimal inflammatory response beneficial for defined cell manipulation, regulatory approval and clinical use. Several recent studies using rodent stem cells demonstrate that PPy doped with bioactive molecules can influence stem cell survival and differentiation. ${ }^{7-9}$ Zhang et al (2010) investigated unstimulated PPy doped with peptides from extra cellular matrix (ECM) protein laminin, and suggest PPy and other CPs have significant potential for engineering "intelligent" substrates 
for controlling stem cell growth. ${ }^{9}$ Lundin et al (2011) investigated the utility of CP substrates combined with electrical stimulation to regulate rat neural stem cell (rNSC) state and fate. ${ }^{8}$ More specifically, electrical stimulation of PPy doped with DBS impaired fetal rNSC survival. Viability of rNSCs was rescued by thickly coating PPy(DBS) films with a gel layer composed of a basement membrane matrix, resulting in cell survival rates comparable to standard rNSC culture conditions (without CP and electrical stimulation).

In spite of the evidence for CPs such as PPy supporting cell growth and differentiation, ${ }^{10-}$

${ }^{11}$ their compatibility with clinically-relevant hNSCs, such as human brain-derived NSCs, and potential as electroactive substrates for controlling human stem cell fate remains undetermined. In this study, we investigated the differentiation of hNSCs on laminin-coated PPy(DBS) with electrical stimulation. To the best of our knowledge, this paper is the first account of human brain tissue derived neural stem cell differentiation and support using electroactive PPy.

\section{Materials and Methods \\ Preparation of Polymer Films}

The Pyrrole (Py) monomer was obtained from Sigma and distilled prior to use. All dopants used for PPy polymerisation, including para-toluene sufonate (pTS), DBS and the sodium salt of chondroitin sulfate (CS) A, were obtained from Sigma. All Py monomer and dopant solutions were prepared with distilled and deionized water $\left(\mathrm{dH}_{2} \mathrm{O}\right.$, Milli-Q). Goldcoated mylar (Solutia Performance Films, CA, USA) was prepared for polymerisation by cleaning with isopropanol and $\mathrm{dH}_{2} \mathrm{O}$, then drying under a $\mathrm{N}_{2}$ stream. Aqueous monomer solutions were prepared separately for each dopant, consisting of $0.2 \mathrm{M}$ Py and either $0.05 \mathrm{M}$ pTS, $0.05 \mathrm{M}$ DBS or $2 \mathrm{mg} / \mathrm{mL}$ CS. These aqueous solutions were degassed using $\mathrm{N}_{2}$ for 10 min prior to polymerization of the polymers. PPy films were polymerized galvanostatically at 
a current density of $0.1 \mathrm{~mA} / \mathrm{cm}^{2}$ for $10 \mathrm{~min}$ in the aqueous monomer solution using an eDAQ EA161 potentiostat. Polymer growth was performed in a standard three-electrode electrochemical cell with the gold-coated mylar as the working electrode, a platinum mesh counter electrode, and $\mathrm{Ag} \mid \mathrm{AgCl}$ reference electrode. After growth, the films were washed extensively with $\mathrm{dH}_{2} \mathrm{O}$, gently dried with $\mathrm{N}_{2}$ gas, and stored under desiccated conditions until use.

\section{Atomic Force Microscopy}

Atomic Force Microscopy (AFM) imaging was performed using a JPK Biowizard II AFM (JPK Instruments, Germany). Polymer samples were prepared for characterisation by washing with $\mathrm{dH}_{2} \mathrm{O}$ and drying with $\mathrm{N}_{2}$. AFM images were obtained in air at $25^{\circ} \mathrm{C}$ using a $0.42 \mathrm{~N} / \mathrm{m}$ silicon nitride cantilever in tapping mode with a scan rate of $0.5-1 \mathrm{~Hz}$. Average roughness $(\mathrm{Ra})$ and Root Mean Square (RMS) roughness $(\mathrm{Rq})$ values were calculated from AFM height images using analysis software of the AFM.

\section{Contact Angle Goniometry}

Contact angle measurements were made with a $2 \mu 1$ water droplet using the sessile drop technique and a DataPhysics OCA20 Goniometer (Germany), employing SCA21 software. At least five measurements were taken on each surface, and the average and standard deviation were calculated.

\section{Cyclic Voltammetry}

Cyclic voltammetry (CV) was performed using a CH Instruments 660D Electrochemical Workstation. The three-electrode cell consisted of a $1 \mathrm{~cm}^{2}$ polymer-coated working electrode, 
a platinum mesh counter and an $\mathrm{Ag} \mid \mathrm{AgCl}$ reference electrode. Measurements were performed in PBS electrolyte, at a scan rate of $10 \mathrm{mVs}^{-1}$ over the potential range -0.6 to $+0.6 \mathrm{~V}$.

\section{Neural Stem Cell Culture and Differentiation}

Working stocks of RenCell CX hNSCs (Millipore; approved for use by the University of Wollongong's Human Research Ethics Committee; HE14/049) were maintained by seeding at a density of 2-3 x $10^{6}$ cells into a low attachment T-75 flask (Corning) containing DMEM/F12 (Invitrogen) based expansion medium supplemented with 2\% B27 (Invitrogen), $2 \mu \mathrm{g} / \mathrm{ml}$ heparin (Sigma), epidermal growth factor (EGF, $10 \mathrm{ng} / \mathrm{ml}$; Peprotech) and basic fibroblast growth factor (bFGF, $20 \mathrm{ng} / \mathrm{ml}$; Peprotech). Once hNSCs formed free-floating neurospheres after 7-14 days, they were passaged for subculture every 5-7 days by digesting in 1-2 $\mathrm{ml}$ TrypLE (Gibco BRL) for $5 \mathrm{~min}$ at $37^{\circ} \mathrm{C}$. Digested neurospheres were triturated to single cells, and plated at a density of $5 \times 10^{4}$ cells $/ \mathrm{ml}$ using ultra-low attachment 6 -well plates (Corning).

hNSCs were differentiated by digesting neurospheres as above and plating $5 \times 10^{4}$ cells $/ \mathrm{cm}^{2}$ onto 8 -well-chamber slides (Nunc) or prepared polymers, coated with $20 \mu \mathrm{g} / \mathrm{ml}$ laminin (Life Technologies) containing 2 parts DMEM F-12: 1 part Neurobasal supplemented with $2 \%$ StemPro (Life Technologies), $0.5 \% \mathrm{~N}_{2}$ (Gibco) and $50 \mathrm{ng} / \mathrm{ml}$ brainderived neurotrophic factor (BDNF; Peprotech) up to 7 days. A half-volume medium change was performed every 2-3 days.

\section{Electrical Stimulation}

For electrical stimulation experiments, cells were seeded at the same density $\left(5 \times 10^{4}\right.$ cells $/ \mathrm{cm}^{2}$ ) in two groups (one electrical stimulation group and one control group). In all groups, cells were seeded in differentiation media onto laminin-coated PPy(DBS) films, as 
described above, and allowed to adhere for 24 hours before the media was topped up and electrical stimulation applied in accordance with published method. ${ }^{12}$ Cells were stimulated for $8 \mathrm{hrs}$ per $24 \mathrm{hrs}$ period for 3 days under $5 \% \mathrm{CO}_{2}$ at $37^{\circ} \mathrm{C}$, after which the cells were either fixed or allowed to differentiate for a further 3 days before fixing for immunostaining and other analyses. Electrical stimulation was performed via a 2-electrode setup, whereby an auxiliary platinum mesh electrode was placed into the media at the top of each well and the PPy coated Au-mylar surface was used as the working electrode. The cells were stimulated at $\pm 0.25 \mathrm{~mA} / \mathrm{cm}^{2}$ using a biphasic waveform of $100 \mu$ s pulses with $20 \mu$ s interphase open circuit potential, and $3.78 \mathrm{~ms}$ short circuit $(250 \mathrm{~Hz})$ using a Digital StimulatorDS8000 and A365 Isolator units (World Precision Instruments) interfaced with an e-corder system (eDAQ). The voltage waveform across the active electrode area in response to the current pulse applied was recorded, and using Ohm's law, total impedance $(\mathrm{Zt})$ was calculated from the peak voltage $(\mathrm{Vt})$ output divided by the applied current $(\mathrm{i})(\mathrm{Zt}=\mathrm{Vt} / \mathrm{i})$, access resistance from the initial voltage drop $(\mathrm{Ra}=\mathrm{Va} / \mathrm{i})$, and polarisation impedance from the remaining voltage drop $(\mathrm{Zp}=\mathrm{Vp} / \mathrm{i})$

\section{Immunocytochemistry and Analysis}

Cell samples were fixed by incubation with a $3.7 \%$ paraformaldehyde solution in PBS. Samples were incubated at room temperature (RT) for 10 min prior to rinsing with PBS. Cell samples were then blocked and permeabilised for $1 \mathrm{hr}$ at $37^{\circ} \mathrm{C}$ in $5 \%(\mathrm{v} / \mathrm{v})$ goat serum in $\mathrm{PBS}$ containing $0.3 \%$ (v/v) Triton X-100 (blocking buffer). Primary antibodies including mouse anti-microtubule-associated protein 2 (MAP2, 1:1000; Sigma), rabbit anti-GFAP (1:1000; Millipore), chicken anti- $\beta$-III Tubulin (Tuj1, 1:1000; Millipore), mouse anti-Ki67 (1:500; BD Bioscience), mouse anti-nestin (1:500; BD Bioscience), rabbit anti-Sox2 (1:500; Millipore), and chicken anti-vimentin (1:1000; Millipore) were diluted in blocking buffer and then 


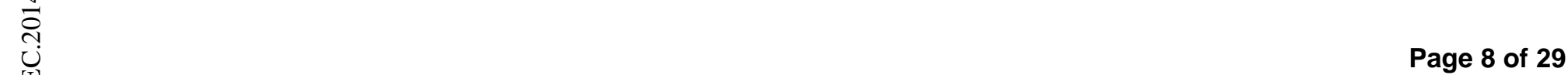

incubated with the cell samples overnight at $4^{\circ} \mathrm{C}$. The cells were then washed $3 \times 5 \mathrm{~min}$ in PBS/0.1\% (v/v) Triton X-100 prior to the addition of an appropriate secondary antibody conjugated with Alexa 594 or 488 (1:1000; Invitrogen) and diluted in blocking buffer. The cells were left for $1 \mathrm{hr}$ at RT. A further 3 x 5 min washes in PBS/0.1\% Triton X-100 were performed prior to a 5 min incubation at RT with $1 \mu \mathrm{g} / \mathrm{mL}$ DAPI in PBS. The DAPI solution was replaced with fresh PBS and cells were then imaged at 10x magnification. Imaging was performed using an AxioImager (Zeiss) fitted with an AxioCAM Mrm camera and overlayed using AxioVison 4 software. Image analysis was performed using MetaMorph software V 7.8 with the neurite analysis plugin for neurite length, number and branching, or ImageJ software for glial vs neural scoring.

\section{Flow Cytometry}

Neurospheres were collected and digested in TrypLE as described above. After trituration, single cells were pelleted and fixed with 3.7\% paraformaldehyde solution in PBS on ice for $10 \mathrm{~min}$. After 2 washes in PBS/0.1\% (v/v) Triton X-100, cells were resuspended in blocking buffer and placed on ice for 20 min. Cells were then incubated with primary antibodies mouse anti-Ki67 (1:500; BD Bioscience), mouse anti-nestin (1:500; BD Bioscience), rabbit anti-Sox2 (1:500; Millipore), and chicken anti-vimentin (1:1000; Millipore) diluted in wash buffer on ice for $30 \mathrm{~min}$. Following a further 2-3 washes, secondary antibodies conjugated with Alexa Fluor-488 and Alexa Fluor-594 (1:1000; Invitrogen) and diluted in blocking buffer were applied for 30 min on ice. Cells were then washed again before being resuspended in PBS and analysed by a BD Accuri C6 system (BD Biosciences).

Scanning Electrochemical Microscopy 
Scanning electrochemical microscopy (SECM) was performed in feedback mode using CH Instruments SECM model 920D utilizing CHI integrated software version 12.26. Pt disk (10 $\mu$ m diameter) ultra-microelectrode (UME; CH Instruments Inc.) was used as the working electrode. Pt mesh and $\mathrm{Ag} / \mathrm{AgCl}(3.0 \mathrm{M} \mathrm{NaCl})$ were used as the counter electrode $(\mathrm{CE})$ and reference electrode (RE) respectively. Feedback mode data collection was performed in cell culture media containing 4 mM analytical-grade Ferrocenemethanol (FcMeOH; Sigma) redox mediator. $\mathrm{FCMeOH}$ was therefore used as the electron transfer mediator to look at the variation of conductivity across the PPy(DBS) surface. The SECM probe was biased at +0.5 V for electro-oxidation of FcMeOH. A 3D SECM image in constant height was obtained by scanning the substrate in the $x-y$ plane with the UME probe and recording the feedback current against probe location to determine local concentration of the redox mediator in solution and the corresponding surface electroactivity. Mean current values were calculated using at least 1000 data points within the area assessed. The probe/substrate separation was adjusted to $3 \mu \mathrm{m}$ using a digital microscope (MEIJI Techno model MS50). Similar methods have previously been described for studying PPy surface conductivity. ${ }^{13-14}$

\section{Scanning Electron Microscopy}

Cells were fixed in a $3.7 \%$ paraformaldehyde solution in PBS for $10 \mathrm{~min}$ at RT and then dehydrated in EtOH prior to Critical Point Drying using a Leica EM CPD030 instrument. Once dried, samples were coated in a $15 \mathrm{~nm}$ layer of gold using an Edwards sputter coater and kept desiccated until imaging was performed. SEM was performed using a JEOL LV SEM operated at an accelerating voltage of $10.0 \mathrm{kV}$ and the secondary electron images were taken with a semi in-lens detector at a working distance of $8 \mathrm{~mm}$.

\section{Statistics}


OriginPro Version 8.6 was used to perform one-way analyses of variance followed by Bonferroni post-hoc analysis.

\section{Results}

Characterisation of different PPy(doped) films

Since substrate properties such as elasticity, ${ }^{15-16}$ roughness,,${ }^{17-18}$ surface charge,${ }^{19-20}$ and wettability, ${ }^{21-22}$ can affect the adhesion, growth and fate of cells, and the dopant type can influence the surface characteristics of CPs, we initially characterized the surface topography of PPy films using AFM, followed by contact angle goniometry (CAG) and CV. AFM showed all of the differently doped films had characteristic 'cauliflower' morphology (Fig. 1). ${ }^{23}$ pTS and CS doped films had similar Ra and Rq values, while DBS doped films were marginally smoother (Table 1; Fig. 1).

The surface wettability of each substrate was determined by CAG. Similar measures of contact angle were determined for all substrates, with each being moderately hydrophilic (ie. less than $90^{\circ}$; Table 1). ${ }^{24}$ Finally, CV demonstrated all PPy(doped) films had well defined electrochemical responses with clear oxidation and reduction peaks indicating the presence of a redox active polymer (Supplementary Fig. 1).

\section{Assessment of hNSC differentiation on unstimulated PPy(doped) films}

Prior to differentiation on PPy films, hNSCs were maintained under conventional culture conditions as self-renewing cells, able to form neurospheres and stably expressing cell proliferation marker Ki-67 and neural stem/progenitor markers vimentin, nestin, and sox-2 (Fig. 2A, B). ${ }^{25}$ Subsequent transfer of hNSCs from standard laminin-coated glass substrate resulted in a differential effect on neuronal induction of hNSCs between PPy films (Fig. 2C, D). Specifically, qualitative assessment of differentiated hNSCs indicated that PPy doped 
with DBS provided the best support of MAP2 positive neurons, with networks of neuritesbeing comparable to standard culture conditions, while CS and pTS doped films provided poor support with cultures comprising relatively few to negligible neurites respectively (Fig. 2C, D). PPy(DBS) was chosen for subsequent experiments involving electrical stimulation.

\section{Differentiation of hNSCs on electroactive PPy(DBS) film}

The scheme for culturing and stimulating hNSCs on doped PPy is illustrated in Fig. 3. The impedances of the PPy(DBS) polymer were monitored for the duration of the hNSC electrical stimulation period. Three impedance values were derived from the resulting voltage waveforms (Fig. 3A), including total impedance $(\mathrm{Zt}=\mathrm{Vt} / \mathrm{i})$, access resistance $(\mathrm{Ra}=\mathrm{Va} / \mathrm{i}$; relating to changes in electrolyte) and polarisation impedance $(\mathrm{Zp}=\mathrm{Vp} / \mathrm{i}$; relating to changes at the electrode surface). ${ }^{12}$ Notably, the Zp showed minimal change during the stimulation period, ranging from $5 \mathrm{ohms}$ at day 1 to $4 \mathrm{ohms}$ at day 3 , indicating electrochemical stability of the PPy(DBS) film during cell stimulation.

Electrical stimulation of PPy(DBS)-based hNSCs altered cell differentiation, as illustrated by immunocytochemistry of neuronal marker Tuj1 and astrocyte marker GFAP, as well as cell distribution and neurite formation (Fig. 4). More specifically, in contrast to unstimulated glass-based and PPy(DBS)-based culture, electrical stimulation of PPy(DBS) induced hNSCs to predominantly Tuj1-expressing neurons, with lower induction of GFAP expressing glial cells (Fig. 4A, B). Secondly, unlike unstimulated cultures, stimulated PPy(DBS)-based cultures comprised nodes or clusters of neurons joined by neurite networks (Fig. 4A). Thirdly, electrically stimulated PPy(DBS)-neurons exhibited a greater total neurite length per cell, mean neurite length and maximum neurite length compared to other treatments (Fig. 4C). Although neurite number and branching was decreased for hNSCs 
differentiated on PPy(DBS) compared to standard glass-based differentiation, electrical stimulation of PPy(DBS) film resulted in a greater number of neurites and increased neurite branching compared to unstimulated cells on film (Fig 4D). Finally, qualitative assessment of scanning electron microscopy (SEM) images supported the presence of fewer astrocytes for elecroactive PPy(DBS)-based differentiation. For all conditions tested, cells exhibited neurite outgrowths, with neurites connecting adjacent cells (Fig. 5). Micrographs also confirm cell attachment to all substrates (Fig. 5).

\section{Assessment of surface conductivity of PPy $(D B S)$ film}

Following the observation of cell clustering on electrically stimulated PPy(DBS) film, we postulated that it may reflect heterogeneous conductivity across the film surface, with areas of higher and lower conductivity potentially underlying high and no cell clustering respectively. We subsequently used SECM to assess conductivity across the surface of the PPy(DBS) film (Fig. 6). The SECM images show a surface that has an inherent conductivity represented by extensive green shading (Fig. 6), with mean ( \pm SD) current values of $4.76 \pm$ $0.07 \mathrm{nA}$ (Fig. 6A) and $4.81 \pm 0.05 \mathrm{nA}$ (Fig. 6B), interposed by regions of higher and lower current representing regions of higher and lower conductivity respectively. The distance between the different regions ranged from 10 - $20 \mu \mathrm{m}$ (Fig. 6), corresponding to the distance between various cell clusters previously observed and shown in Figure 4A.

\section{Discussion}

This study adds to the growing body of evidence for using electrical stimulation and CPs with bioactive dopants to influence the culture and differentiation of stem cells. We specifically report the differentiation of hNSCs to neurons and glia on laminin-coated PPy(DBS), with a higher proportion of neurons and lower glial cell numbers following 
electrical stimulation. Neurons exhibited clustering and increased neurite growth, with the latter manifesting as longer neurites with greater branching. Alternatively, standard laminincoated glass-based differentiation of unstimulated hNSCs had greater numbers of shorter neurites with less branching.

Since AFM and CAG studies showed negligible differences between the surface roughness and contact angles of different substrates, it is unlikely that surface topography and surface energy influenced neuronal induction. Notwithstanding the potential effects of other properties (eg. interacting surface chemistry) on the biocompatibility of a specific polymer/dopant system, ${ }^{8,26-27}$ our initial observation of unstimulated PPy(DBS) supporting neuronal induction affirmed further studies with electrical stimulation.

The observed tendency towards neuronal induction using electroactive PPy(DBS) extends the findings of Yamada et al who report electrical stimulation causes murine EBs to differentiate "somewhat specifically" into neuronal cells. ${ }^{2}$ Importantly, while the overall composition of neurons and glial cells in the human brain remains contentious, with conventional opinion holding that glial cells are more numerous than neurons by a factor of 10, and more recent reports suggesting a smaller glia/neuron ratio of approximately $1: 1$, since the glia/neuron ratio varies between different areas of the brain, there is a need for methods to modulate the proportion of glial to neuronal cells for region specific modelling in vitro and tissue engineering for transplantation therapy. ${ }^{28}$ To this end, based on our findings, electroactive PPy(DBS) might be useful to influence the tissue content of neurons and glia derived from hNSCs and potentially other stem cell types of human origin.

The pattern of cell clustering associated with electrical stimulation was unexpected, although a similar phenomenon has been reported for primary rat hippocampal neurons cultured on microelectrode arrays (MEAs). ${ }^{29}$ Also, we have previously reported variable conductivity across the surfaces of PPy films, where nodular regions of polymer correlated 
with high current and extracellular matrix protein adhesion. ${ }^{30}$ Our earlier findings, however, relate to nano-scale variation with phase separation in conductivity measured across $0.3-0.4$ $\mu \mathrm{m}$, whereas the present cell clustering occurred with micron resolution. Nonetheless, it is conceivable that areas of high conductivity presently measured are also associated with increased cell adhesion and/or galvanotaxis. While for now we can only surmise the cause of the heterogeneous conductivity, with one possibility being a heterogenous doping of the polymer, our findings suggest that modulation of conductivity and electroactivity of PPy(DBS) film and more broadly cell culture substrates can potentially be used to regulate maturation and organisation of neural networks in vitro or in vivo.

In summary, the results presented here illustrate the utility of electrical stimulation and the biocompatibility of electroactive $\mathrm{PPy}(\mathrm{DBS})$ for differentiating clinically-relevant human brain NSCs. The hNSCs described are self-renewing and multipotent, able to differentiate into multiple neural cell types, and have the potential to be used for both research and as a therapy for neurological diseases. ${ }^{25,31}$ Similarly, as a cytocompatible CP, PPy can be used for research and as a clinical device. Therefore, by interfacing hNSCs with electroactive PPy we have demonstrated a biologically relevant method for enhanced delivery of human neuronal tissues for research and clinical application.

\section{Achnowledgements}

The authors wish to acknowledge the use of facilities at the University of Wollongong Electron Microscopy Centre, ongoing financial support of the Australian Research Council (ARC) and the ARC Centre of Excellence for Electromaterials Science (ACES), support and assistance by the Australian National Fabrication Facility (ANFF) - Materials Node, and Mr Hongrui Zhang for assisting with AFM. Professor Gordon Wallace acknowledges the support of the ARC through an ARC Laureate Fellowship - the primary funding source for this work. 
The authors would like to dedicate this paper to Dr. Nao Kobayashi, a remarkable colleague and cherished friend. Nao's passion and dedication to her scholarship was unparalleled and her friendship and caring spirit will be missed.

\section{Disclosure Statement}

No competing financial interests exist.

\section{References}

1. Srivastava, N., Venugopalan, V., Divya, M.S., Rasheed, V.A., James, J., andNarayan, K.S. Neuronal differentiation of embryonic stem cell derived neuronal progenitors can be regulated by stretchable conducting polymers. Tissue Eng Part A 19, 1984, 2013.

2. Yamada, M., Tanemura, K., Okada, S., Iwanami, A., Nakamura, M., Mizuno, H., Ozawa, M., Ohyama-Goto, R., Kitamura, N., Kawano, M., Tan-Takeuchi, K., Ohtsuka, C., Miyawaki, A., Takashima, A., Ogawa, M., Toyama, Y., Okano, H., and Kondo, T. Electrical stimulation modulates fate determination of differentiating embryonic stem cells. Stem cells 25, 562, 2007.

3. Mycielska, M.E. and Djamgoz, M.B. Cellular mechanisms of direct-current electric field effects: galvanotaxis and metastatic disease. J Cell Sci 117, 1631, 2004.

4. Cameron, I.L., Hardman, W.E., Winters, W.D., Zimmerman, S., and Zimmerman, A.M. Environmental magnetic fields: influences on early embryogenesis. J Cell Biochem 51, 417, 1993.

5. Zhao, M. Electrical fields in wound healing-An overriding signal that directs cell migration. Semin Cell Dev Biol 20, 674, 2009.

6. Robinson, K.R. The responses of cells to electrical fields: a review. J Cell Biol 101, 2023, 1985. 
7 Herland, A., Persson, K.M., Lundin, V., Fahlman, M., Berggren, M., Jager, E.W., and Teixeira, A.I. Electrochemical control of growth factor presentation to steer neural stem cell differentiation. Angewandte Chemie 50, 12529, 2011.

8. Lundin, V., Herland, A., Berggren, M., Jager, E.W., and Teixeira, A.I. Control of neural stem cell survival by electroactive polymer substrates. PloS one 6, e18624, 2011.

9. Zhang, L., Stauffer, W.R., Jane, E.P., Sammak, P.J., and Cui, X.T. Enhanced differentiation of embryonic and neural stem cells to neuronal fates on laminin peptides doped polypyrrole. Macromolecular bioscience 10, 1456, 2010.

10. Collier, J.H., Camp, J.P., Hudson, T.W., and Schmidt, C.E. Synthesis and characterization of polypyrrole-hyaluronic acid composite biomaterials for tissue engineering applications. Journal of biomedical materials research 50, 574, 2000.

11. Garner, B., Georgevich, A., Hodgson, A.J., Liu, L., and Wallace, G.G. Polypyrroleheparin composites as stimulus-responsive substrates for endothelial cell growth. Journal of biomedical materials research 44, 121, 1999.

12. Richardson, R.T., Thompson, B., Moulton, S., Newbold, C., Lum, M.G., Cameron, A., Wallace, G., Kapsa, R., Clark, G., and O'Leary, S. The effect of polypyrrole with incorporated neurotrophin-3 on the promotion of neurite outgrowth from auditory neurons. Biomaterials 28, 513, 2007.

13. Arca, M., Mirkin, M.V., Bard, A.J. Polymer films on electrodes. 26. Study of ion transport and electron transfer at polypyrrole films by scanning electrochemical microscopy. J Phys Chem. 99, 5040-5050, 1995.

14. C. Kranz, C, Wittstock, G., Wohlschläger, H., Schuhmann, W. Imaging of microstructured biochemically active surfaces by means of scanning electrochemical microscopy. Electrochim. Acta. 42, 3105-3111, 1997. 
15. Engler, A.J., Sen, S., Sweeney, H.L., and Discher, D.E. Matrix elasticity directs stem cell lineage specification. Cell 126, 677, 2006.

16. Discher, D.E., Janmey, P., and Wang, Y.L. Tissue cells feel and respond to the stiffness of their substrate. Science 310, 1139, 2005.

17. Spatz, J.P. and Geiger, B. Molecular engineering of cellular environments: cell adhesion to nano-digital surfaces. Methods Cell Biol 83, 89, 2007.

18. Vogel, V. and Sheetz, M. Local force and geometry sensing regulate cell functions. Nat

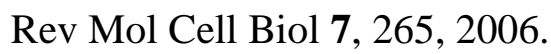

19. Ohgaki, M., Kizuki, T., Katsura, M., and Yamashita, K. Manipulation of selective cell adhesion and growth by surface charges of electrically polarized hydroxyapatite. $\mathrm{J}$ Biomed Mater Res 57, 366, 2001.

20. Xu, Y., Takai, M., and Ishihara, K. Protein adsorption and cell adhesion on cationic, neutral, and anionic 2-methacryloyloxyethyl phosphorylcholine copolymer surfaces. Biomaterials 30, 4930, 2009.

21. Velzenberger, E., El Kirat, K., Legeay, G., Nagel, M.D., and Pezron, I. Characterization of biomaterials polar interactions in physiological conditions using liquid-liquid contact angle measurements: relation to fibronectin adsorption. Colloids Surf B Biointerfaces 68, 238, 2009.

22. Wei, J., Igarashi, T., Okumori, N., Maetani, T., Liu, B., and Yoshinari, M. Influence of surface wettability on competitive protein adsorption and initial attachment of osteoblasts. Biomed Mater 4, 045002, 2009.

23. Thompson, B.C., Moulton, S.E., Ding, J., Richardson, R., Cameron, A., O'Leary, S., Wallace, G.G., and Clark, G.M. Optimising the incorporation and release of a neurotrophic factor using conducting polypyrrole. J Control Release 116, 285, 2006. 
24. Forch, R., Schonherr, H., and Jenkins, A.T.A. Contact Angle Ganiometry. In: Forch R., Schonherr H., Jenkins A.T.A., eds. Surface design: applications in bioscience and nanotechnology. Weinheim, Germany: Wiley-VCH; 2009. pp. 471.

25. Kobayashi, N.R., Sui, L., Tan, P.S., Lim, E.K., Chan, J., Choolani, M., and Crook, J.M. Modelling disrupted-in-schizophrenia 1 loss of function in human neural progenitor cells: tools for molecular studies of human neurodevelopment and neuropsychiatric disorders. Mol Psychiatry 15, 672, 2010.

26. Barisci, J.N., Stella, R., Spinks, G.M., and Wallace, G.G. Characterisation of the topography and surface potential of electrodeposited conducting polymer films using atomic force and electric force microscopies. Electrochimica Acta 46, 519, 2000.

27. Fonner, J.M., Forciniti, L., Nguyen, H., Byrne, J.D., Kou, Y.F., Syeda-Nawaz, J., and Schmidt, C.E. Biocompatibility implications of polypyrrole synthesis techniques. Biomed Mater 3, 034124, 2008.

28. Azevedo, F.A., Carvalho, L.R., Grinberg, L.T., Farfel, J.M., Ferretti, R.E., Leite, R.E., Jacob Filho, W., Lent, R., and Herculano-Houzel, S. Equal numbers of neuronal and nonneuronal cells make the human brain an isometrically scaled-up primate brain. $\mathbf{J}$ Comp Neurol 513, 532, 2009.

29. Jun, S.B., Hynd, M.R., Smith, K.L., Song, J.K., Turner, J.N., Shain, W., and Kim, S.J. Electrical stimulation-induced cell clustering in cultured neural networks. Med Biol Eng Comput 45, 1015, 2007.

30. Gelmi, A., Higgins, M.J., and Wallace, G.G. Quantifying fibronectin adhesion with nanoscale spatial resolution on glycosaminoglycan doped polypyrrole using Atomic Force Microscopy. Biochim Biophys Acta 1830, 4305, 2013. 


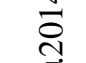

31. Donato, R., Miljan, E.A., Hines, S.J., Aouabdi, S., Pollock, K., Patel, S., Edwards, F.A., and Sinden, J.D. Differential development of neuronal physiological responsiveness in two human neural stem cell lines. BMC Neurosci 8, 36, 2007.

Reprint Author:

Jeremy M. Crook, BSc (Hons), PhD

ARC Centre of Excellence for Electromaterials Science, Intelligent Polymer Research

Institute, AIIM Facility, Innovation Campus, University of Wollongong, Squires Way, Fairy

Meadow, New South Wales 2519, Australia

\section{Figure Captions}




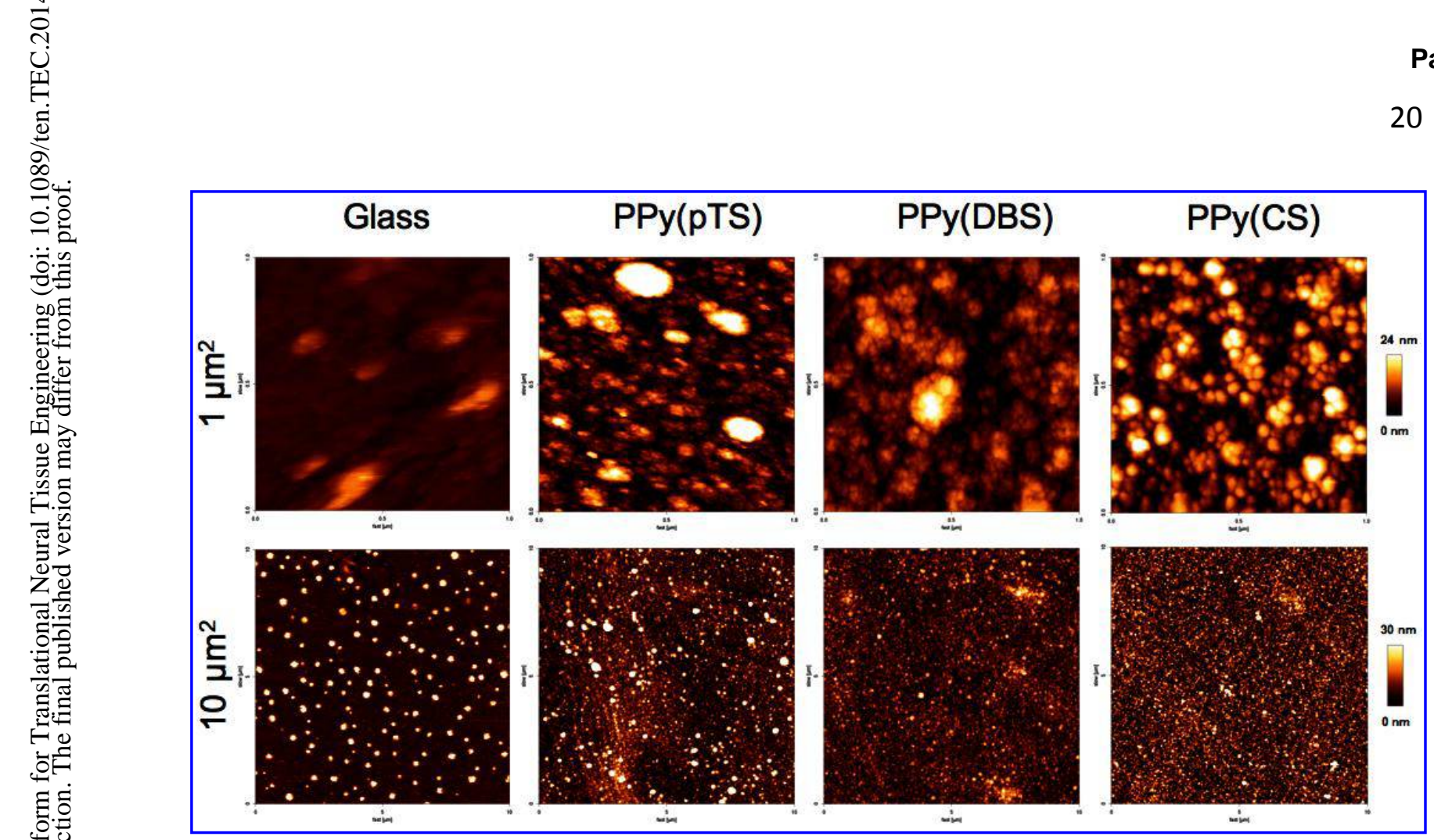

Fig. 1. Characterisation of material properties. AFM images of the topography of substrates tested. 


\section{苛age 21 of 29}

馬

.

రृ:를

이묘

.

赔

㝳

$\cong$

을.

क क

है

Z

을

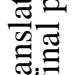

$\exists$

휼

छ

壳

过

\&

음주
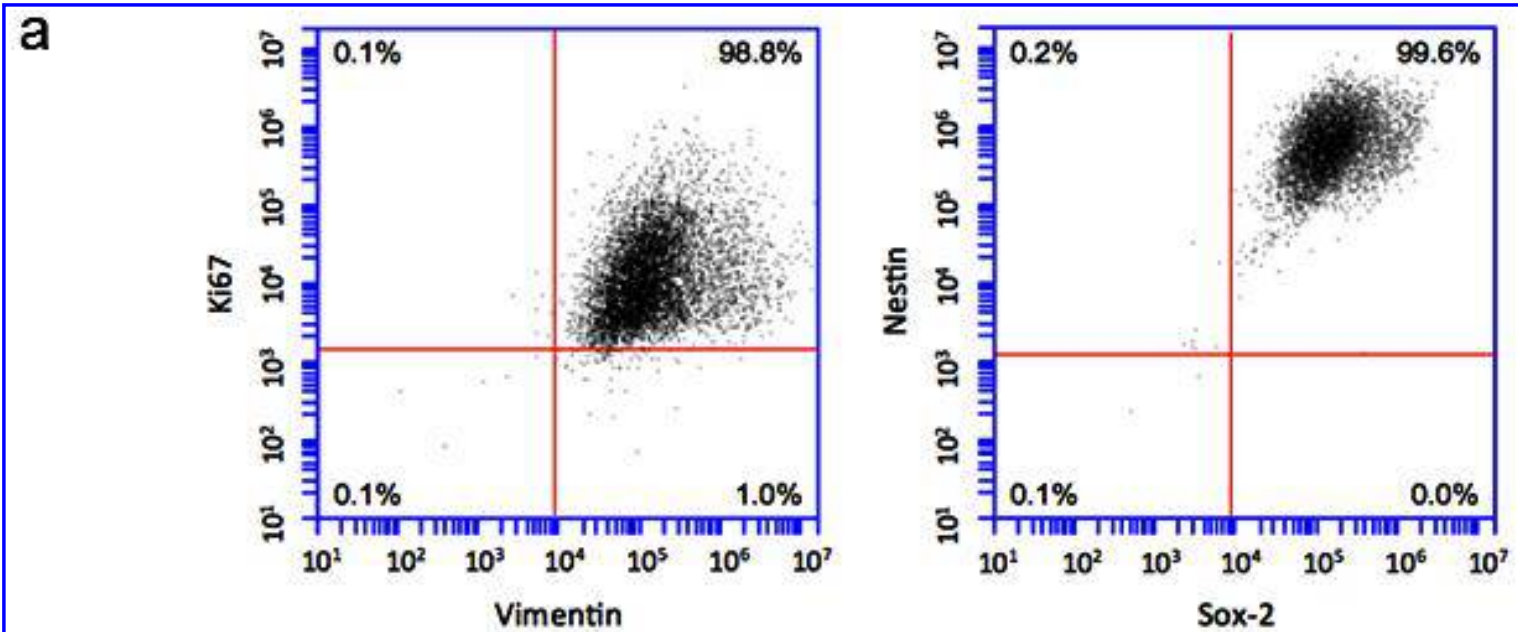

b
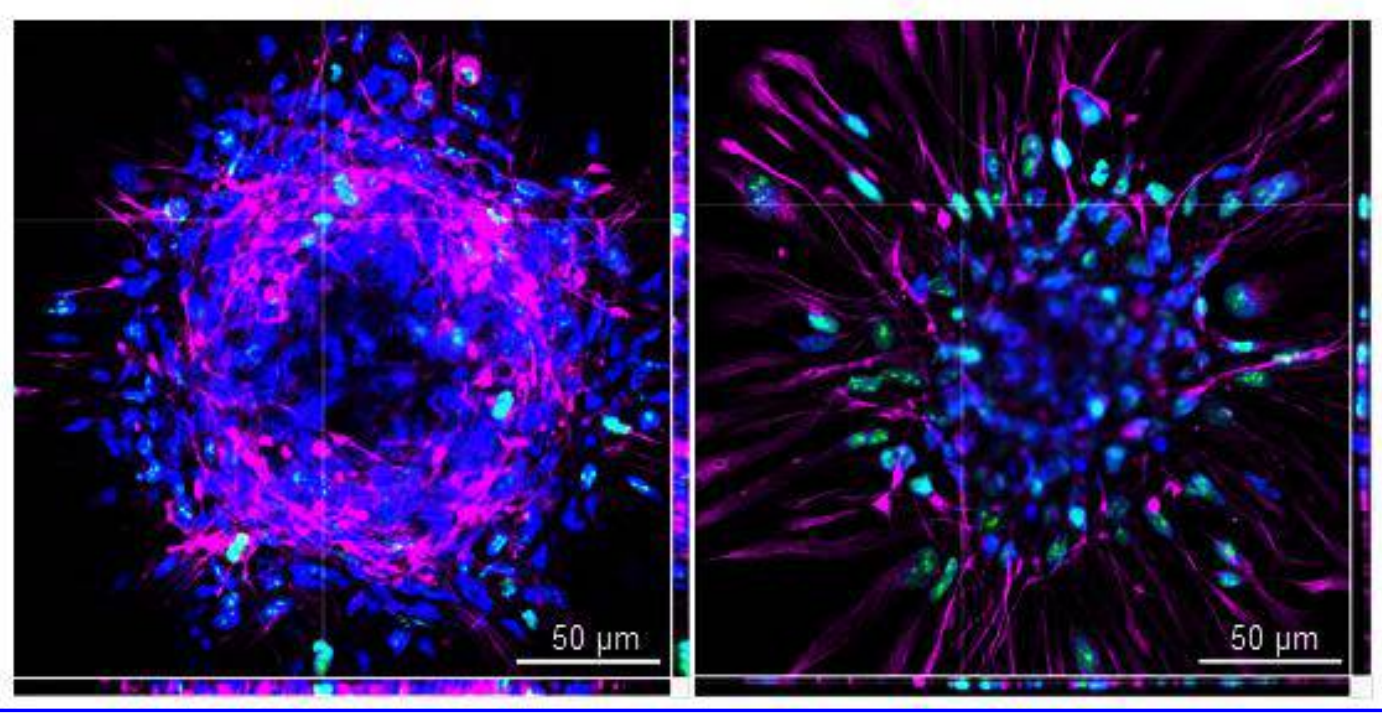


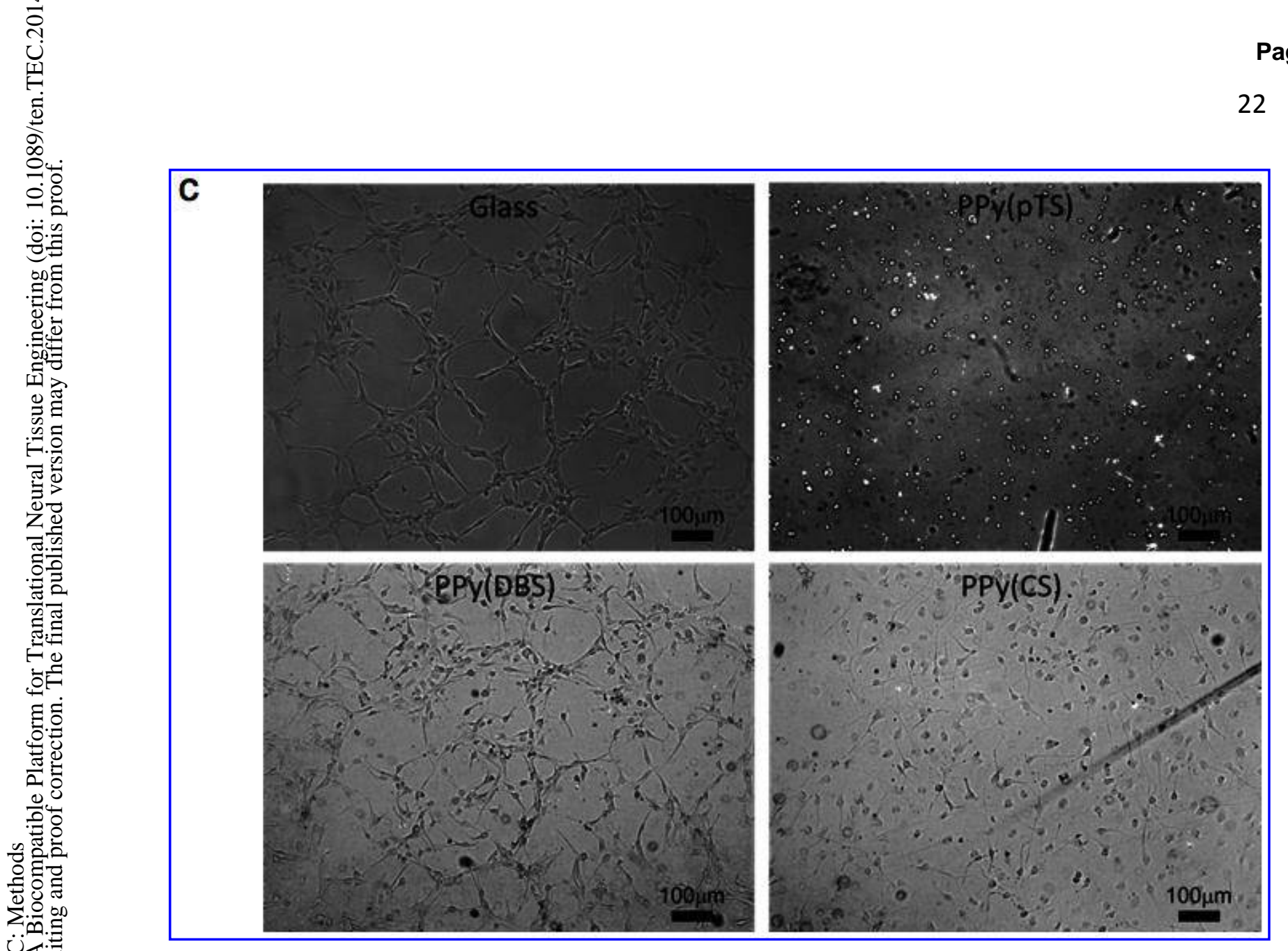

Page 22 of 29

22

节事

oxo :

E

迹

60중

되형ㅇ

Z

促

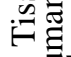

焉

낭

를을

:

w

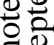

है:

음

응

5

20

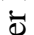

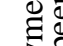

잉

$>0$

牙

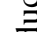

อี.

.0pa

鹖

ธ

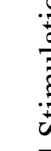




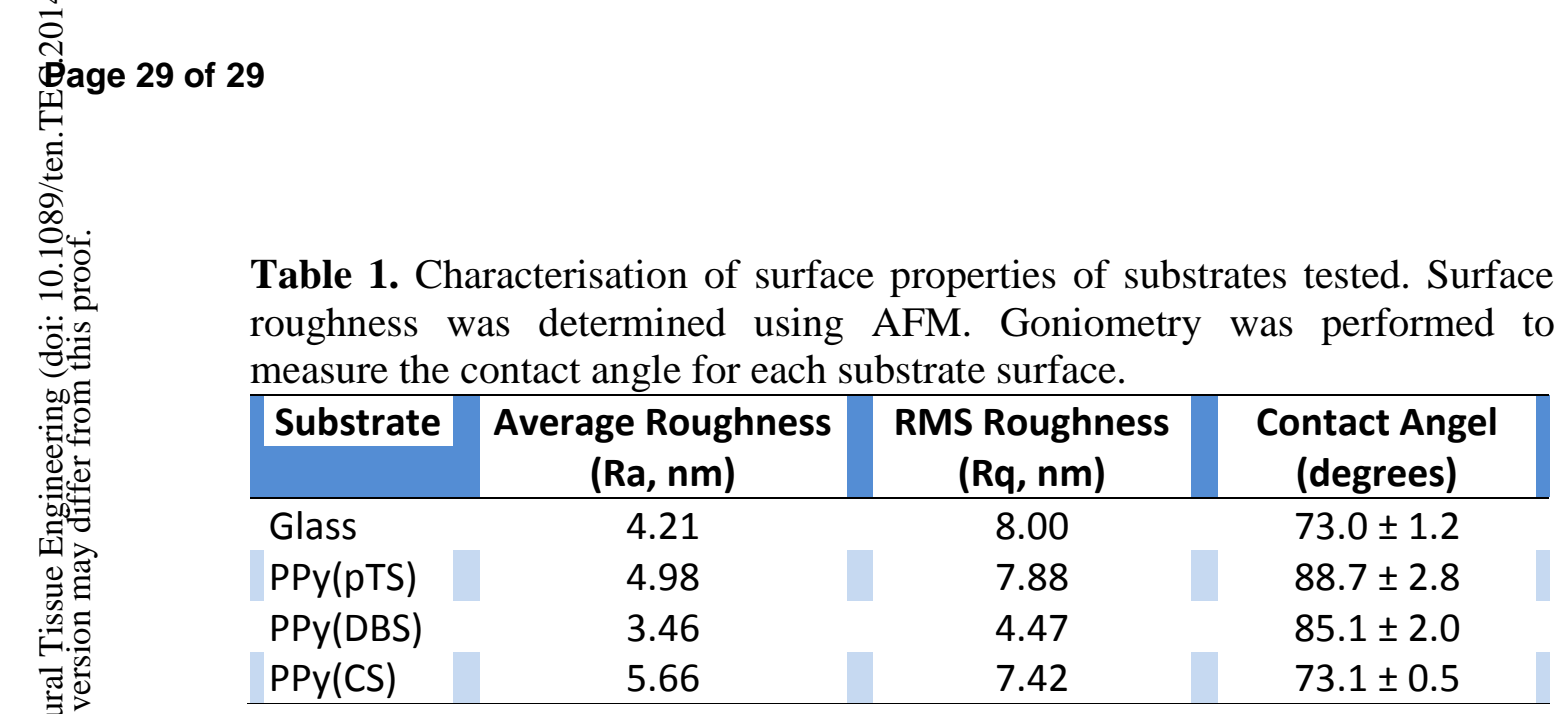

Table 1. Characterisation of surface properties of substrates tested. Surface roughness was determined using AFM. Goniometry was performed to measure the contact angle for each substrate surface. 